IP Periodica Polytechnica

Transportation Engineering

47(2), pp. 111-117, 2019

https://doi.org/10.3311/PPtr. 10609

Creative Commons Attribution (i)

RESEARCH ARTICLE

\section{Simulator Demonstrations of Different Retrofit Options of a Self-propelled Inland Vessel}

\author{
Csaba Hargitai ${ }^{1 *}$, Juha Schweighofer ${ }^{2}$, Győző Simongáti ${ }^{1}$
}

Received 28 July 2016; accepted 18 February 2017

\begin{abstract}
The project MoVe IT! (www.moveit-fp7.eu), funded by the Seventh Framework Programme of the European Union, was focussed on modernisation of inland waterway vessels by retrofitting. In order to stimulate an implementation of the results by the industry, visualization of the positive impacts was realised by a set of vivid demonstrators. In this paper, the demonstrations by simulators for a single screw motor cargo vessel of the type Johann Welker are described.
\end{abstract}

The motion simulations are carried out by a custom made (for inland vessels developed) computer program, which use common naval architect force calculation algorithms and a new approximation theory for added masses.

The simulator demonstrations comprise descriptions and visualisations of ship lengthening, application of different rudder and a new propulsion device. Five different cases are examined, the original vessel and four retrofit options.

First retrofit variant is the lengthened vessel with original rudder and propeller. Other two analysis are performed changing only the rudder system. In fourth simulator demonstration the original propeller is changed to a pump propeller (a novel propulsion device).

The environment are in the simulator demonstrations: constant draught of the vessel, and calm, infinite deep waterway.

As results of simulator demonstrations the effects on fuel consumption and manoeuvrability are discussed in the paper.

\section{Keywords}

inland navigation, vessel retrofitting, simulation, manoeuvring

\footnotetext{
${ }^{1}$ Department of Aeronautics, Naval Architecture and Railway Vehicles, Faculty of Transport Engineering and Vehicle Engineering, Budapest University of Technology and Economics, H-1111 Budapest, Mủegyetem rkp. 3., Hungary

${ }^{2}$ via donau - Österreichische Wasserstraßen GmbH, A-1220 Vienna, Donau City Str. 1., Austria

*Corresponding author, e-mail: cshargitai@vrht.bme.hu
}

\section{Introduction}

In general, identical framework conditions are not present in real-life demonstrations, which makes a quantitative evaluation of the improvements associated with the application of different technical solutions often very difficult, constituting a great, complex challenge.

On the field of vehicle development and research the computer simulation techniques cover wide range of analysis of vehicle motions and control (e.g.: aircraft design (Jankovics et al., 2010), pilot's reaction time measurement under pressure (Nagy et al., 2012), aircraft landing technology development (Rohács et al., 2014), etc.)

In naval architecture the motion simulators can be used in order to demonstrate the improvement expected of a certain single technical solution under predefined framework conditions, representing the environment the vessel is expected to sail in. Simulator demonstrations are cost effective, practical and allow for a qualitative and a quantitative evaluation of the effects of different technologies to be considered as comparative evaluations can be performed under the same framework conditions. A further advantage of using simulators relates to the provision of comprehensive information on physical phenomena and quantities around a vessel, including possibilities for vivid visualisations. Shortcomings relate to the accuracy of the models used and input provided to the simulators, which have to be considered in the respective analysis to be carried out.

\section{Description of the simulator of BME}

The demonstrations described in this paper are based on the 2D ship manoeuvring simulator developed by the Department of Aeronautics, Naval Architecture and Railway Vehicles of the Budapest University of Technology and Economics. The dynamic model is intended to simulate ship manoeuvres by giving the actual position, speed and course of the ship on the fairway due to the real time control of helmsman taking also the actual environmental conditions into consideration (Hargitai et al., 2007).

The $3 \mathrm{DoF}$ motion equations of the simulation use naval architect force models. (Eq. (1)) 


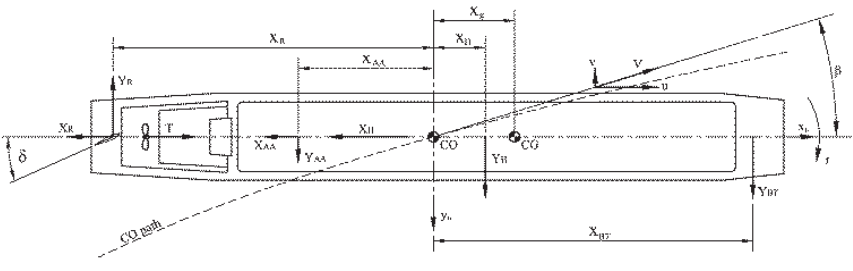

Fig. 1 Forces acting on an inland vessel

where

$\mathrm{X}_{\mathrm{H}}, \mathrm{Y}_{\mathrm{H}}$ : Longitudinal and transversal hydrodynamic forces on hull

$\mathrm{T}:$ Propeller thrust

$\mathrm{X}_{\mathrm{R}}, \mathrm{Y}_{\mathrm{R}}$ : Longitudinal and transversal force on rudder

$\mathrm{X}_{\mathrm{AA}}, \mathrm{Y}_{\mathrm{AA}}$ : Longitudinal and transversal wind resistance

$\mathrm{Y}_{\mathrm{BT}}$ : Transversal force of bow thruster

$$
\begin{aligned}
& T=c_{T}^{*} \frac{\rho_{\text {water }}}{2}\left[((1-w) u)^{2}+(0.7 D \pi \cdot n)^{2}\right] \frac{\pi}{4} D^{2} \\
& X_{R}=c_{K x}(\delta) \frac{\rho_{\text {water }}}{2}\left((1-w) u \cdot \sqrt{\left.1+\frac{T}{\frac{\rho_{\text {water }}}{2} \frac{D^{2} \pi}{4}(1-w) u}\right)^{2}} A_{R}\right. \\
& Y_{R}=c_{K y}(\delta) \frac{\rho_{\text {water }}}{2}\left((1-w) u \cdot \sqrt{\left.1+\frac{\rho_{\text {water }} \frac{D^{2} \pi}{4}(1-w) u}{2}\right)^{2}} A_{R}\right. \\
& X_{A A}=c_{w x} \frac{\rho_{\text {air }}}{2} v_{\text {wind }}^{2} \cdot A_{w x} \\
& Y_{A A}=c_{\text {wy }} \frac{\rho_{\text {air }}}{2} v_{\text {wind }}^{2} \cdot A_{w y} \\
& X_{H}=\frac{\left(c_{F}+c_{R}\right) \cdot \frac{\rho_{\text {water }}}{2} \cdot u^{2} \cdot S}{1-t} \\
& Y_{H}=\frac{\rho_{\text {water }}}{2} c_{\text {lat }} \int_{0}^{L_{w l}}\left[v+\left(x-x_{C G}\right) \frac{d \beta}{d t}\right]^{2} A_{\text {lat }}(x) \cdot d x
\end{aligned}
$$

The force models contain theoretical calculation or model test based parameters of the analysed vessel and the environmental conditions. The main and most important parameters are:

- w: Taylor wake fraction

- D: propeller diameter

- $\mathrm{n}$ : propeller speed of revolution

- $\mathrm{c}_{\mathrm{T}}^{*}$ : thrust force coefficient

- $\mathrm{c}_{\mathrm{Kx}}$ and $\mathrm{c}_{\mathrm{KY}}$ : rudder force coefficients

- $\mathrm{A}_{\mathrm{R}}$ : rudder lateral area

- $\mathrm{c}_{\mathrm{wx}}$ and $\mathrm{c}_{\mathrm{wy}}$ : wind resistance coefficients

- $\mathrm{A}_{\mathrm{wx}}$ and $\mathrm{A}_{\mathrm{wy}}$ :wind areas of ship in longitudinal and trans versal direction

- $\mathrm{c}_{\mathrm{F}}$ : hull friction resistance coefficient

- $\mathrm{c}_{\mathrm{R}}$ : hull residual resistance coefficient

- $\mathrm{t}$ : thrust deduction fraction

- S: wetted area of hull

- $\mathrm{c}_{\text {lat }}$ : lateral force coefficient

- $\mathrm{x}_{\mathrm{CG}}$ : longitudinal coordinate of centre of gravity from stern

- $\mathrm{A}_{\text {lat }}$ : lateral area of hull
These predefined parameters can be modified in a wide range, ensuring the high variety of the different manoeuvring simulation cases (such as the actual loading and flotation, added masses, lateral and wind area of the vessel, engine power, propulsion and rudder system of the ship, and in the meantime the actual wind and flow speed, the banks and the natural and artificial obstacles - like bridges, locks and port entrances, etc. and many more other parameters of the navigational route). The high number of the variable parameters give high flexibility in simulation to the program.

The vessel control in simulation is executed real time by the program operator with changing rudder angle, charge of bow thruster and main engine.

Effect of shallow water on ship resistance is also taken into consideration by Lackenby method (Bertram, 2012), but for comparing ship configuration this report define ideal, infinite deep calm water as fairway.

In the motion simulation the added masses are calculated with a new approximation method. It is based on the calculation of water momentum thickness around the vessel. Using this theory the longitudinal added mass $\left(\lambda_{11}\right)$, the transversal added mass $\left(\lambda_{22}\right)$ and the added inertia $\left(\lambda_{66}\right)$ :

$$
\begin{gathered}
\lambda_{11} \cong-\rho S \frac{L_{W L}}{8}\left(5.14 C_{F x}+C_{R x}\right) \\
\lambda_{22} \cong-\rho S \frac{B_{W L}}{8}\left(5.14 C_{F y}+C_{R y}\right) \\
\lambda_{66} \cong \frac{L_{W L}^{2}}{2} \lambda_{11}
\end{gathered}
$$

where

$\mathrm{L}_{\mathrm{wL}}$ : Length of waterline

$\mathrm{B}_{\mathrm{WL}}$ : Breadth of waterline

However, the program can be used in case of sea-going vessels too, the main goal of the development was to determine and assess the manoeuvrability of particular inland vessels or convoys sailing along critical nautical sections.

The software's screen shows the vessel's motions realtime during simulation, and the trajectory of ship can be also displayed after. All engine, rudder, and bow-thruster related control data can be adjusted and the most important motion parameters (such as speed, rate of turn, position, heading angle, engine revolution, rudder angle, wind speed, current speeds, etc.) are also displayed and stored in a database during simulation. The vessel is displayed with red left and green right sided rectangle by which its direction can be determined.

Result of simulation is highly depending on accuracy of the empirical parameters of motion equations. (e.g.: resistance coefficients of ship, rudder force coefficients, etc.) The 
empirical parameters can be calculated based on test results (high simulation accuracy) or can be estimated by common calculation methods of naval architecture (lower accuracy).

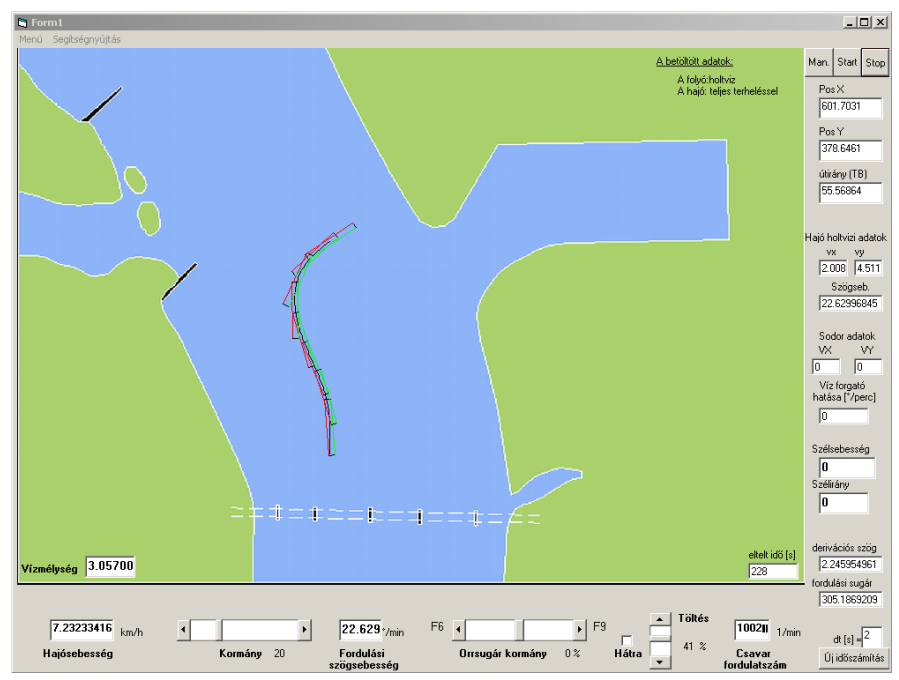

Fig. 2 Screen of simulation software

\section{Object of the demonstration}

The HERSO I is a self-propelled vessel of the Johann Welker-type. The vessel has one main engine with a propeller in nozzle in a tunnel. She has a conventional rudder system with 4 rudder blades and a bow thruster.

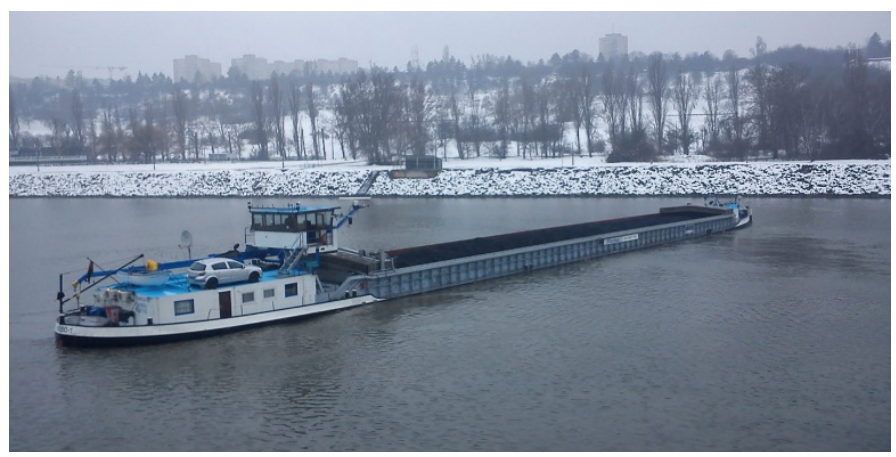

Fig. 3 MV HERSO 1 at Port of Dunaújváros

The main particulars relevant for the demonstration are shown in Table 1.

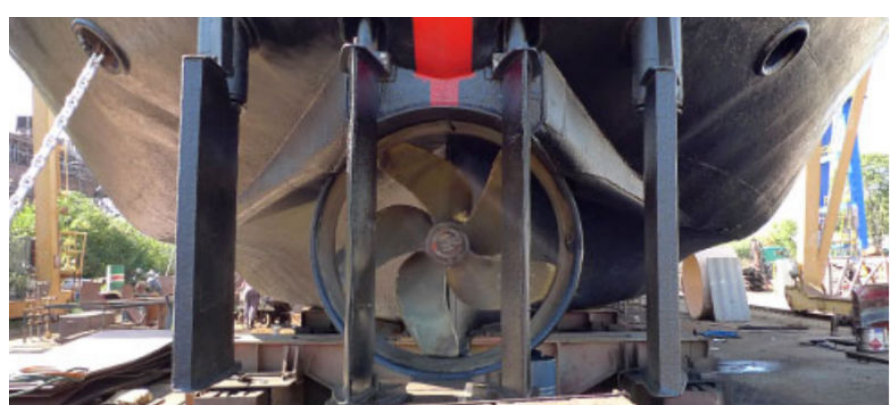

Fig. 4 Screw, tunnel, nozzle and rudder arrangement fitten on the HERSO 1
Table 1 Main particulars of MV HERSO 1

\begin{tabular}{llc}
\hline & \multicolumn{1}{c}{ Particular } & Value \\
\hline \multirow{2}{*}{ LOA } & Building year & 1962 \\
LPP & Ship length over all & $84.95 \mathrm{~m}$ \\
LWL & Length between perpendiculars & $83.50 \mathrm{~m}$ \\
Tmax & Length of waterline & $84.50 \mathrm{~m}$ \\
Bmoulded & Maximum draught & $2.70 \mathrm{~m}$ \\
V & Breadth moulded & $9.5 \mathrm{~m}$ \\
Depl & Speed of the vessel - with barge fully loaded & $11 \mathrm{~km} / \mathrm{h}$ \\
LSW & Displacement at Tmax & $1977.5 \mathrm{t}$ \\
Cargomax & Light ship weight & $596.0 \mathrm{t}$ \\
& Cargo capacity at Tmax & $1381.5 \mathrm{t}$ \\
& Weight of supplies \& outfitting & $130.8 \mathrm{t}$ \\
& Main engine power (Deutz RBV 8M 545) & $780 \mathrm{~kW}$ \\
& Maximum engine RPM & $3931 / \mathrm{min}$ \\
& Propulsion configuration & directly driven \\
& Propeller & 5 bladed FPP \\
& Propeller diameter & $1.55 \mathrm{~m}$ \\
\hline
\end{tabular}

In this paper the effects on manoeuvring of the following three different retrofit options are demonstrated for Herso 1:

- Option No. 1.: Lengthening of ship hull

For increasing load capacity by the same draft MoVeIT! D7.1 System Integration report (MoVeIT! project, 2013a) examined the lengthening retrofit option of Herso 1. Based on this report simulator demonstration of the vessel analyse the lengthening effect on manoeuvring. The empirical parameters for dynamic model are based on resistance calculation method of Holtrop and the rudder force coefficients are defined according to (Brix, 1992). The method of Holtrop was developed for seagoing vessels. Therefore, the speeds presented in the following chapter may be slightly overestimated. Unfortunately, for inland waterway vessels, no suitable general resistance-power calculation method is available, in contrast to seagoing vessels.

- Option No. 2.: Change of rudder configuration

Other option for reducing fuel consumption is to decrease the resistance of rudder. Three different rudder configuration are compared in simulator demonstrations of Herso 1.

First is the original rudder, which has 4 rudder blades with conventional profile and $10.08 \mathrm{~m}^{2}$ total rudder area.

In case of the second rudder configuration the outermost blades are removed, and the rudder profile is changed to fishtail profile. Due to these changes the 2 rudder bladed fishtail rudder configuration has $6.5 \mathrm{~m}^{2}$ total rudder area.

The third rudder configuration is the 3 bladed Jenckel-type rudder system, which has $7.5 \mathrm{~m}^{2}$ total rudder area.

During simulator demonstrations of different rudder configuration - beside the rudder area - only the rudder force coefficients are changed. These are based on (Brix, 1992) and model test results (VEB, 1973). 
- Option No. 3.: Pump propeller (Ship Studio solution)

Third retrofit option examined by simulator demonstration is the change of propeller according to MoVeIT! D2.2_Propeller upgrade report (MoVeIT! project, 2013b). To analyse the change in ship velocity and manoeuvrability the KT and KQ data for 4 quadrants of the original Ka4-70 19A ( $\mathrm{P} / \mathrm{D}=1.175)$ propeller is used. Unfortunately the $\mathrm{KT}$ and $\mathrm{KQ}$ data for 4 quadrants are not available for Pump propeller. That is why they are extrapolated and estimated form KT and KQ data in function of propeller advance factor $(\mathrm{J})$

For each option several cases are compared to demonstrate the effects of an option on manoeuvring. These are summarised in the Table 2.

For all cases impacts of the environment are excluded (no wind, no current - the simulations are performed in calm water). The consequence of lengthening (Fig. 5) is demonstrated by comparing Case 1 and Case 2. The effects of changing rudder arrangement (Fig. 6) are shown by the comparison of Case 1 with Case 3 and 4. And the results of use of a Pump propeller (Fig. 7) can be obtained by comparing Case 1 with Case 5 .

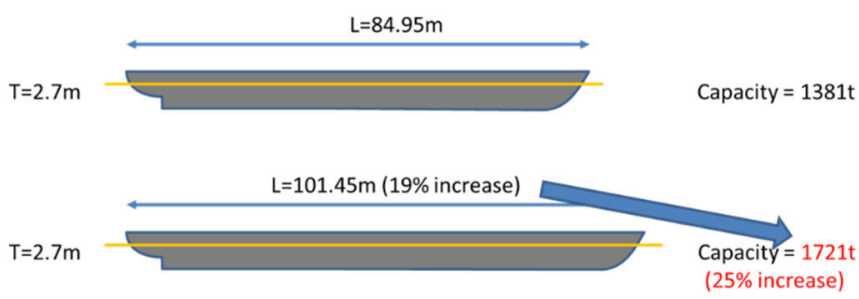

Fig. 5 Retrofit option No.1: Ship hull lengthening
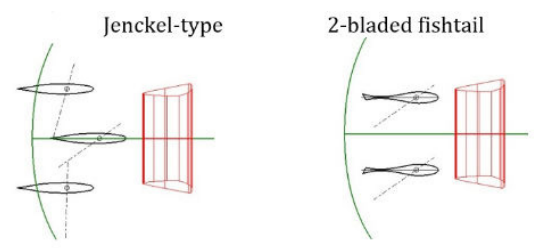

4-bladed original

Fig. 6 Retrofit option No.2: Rudder configuration changes

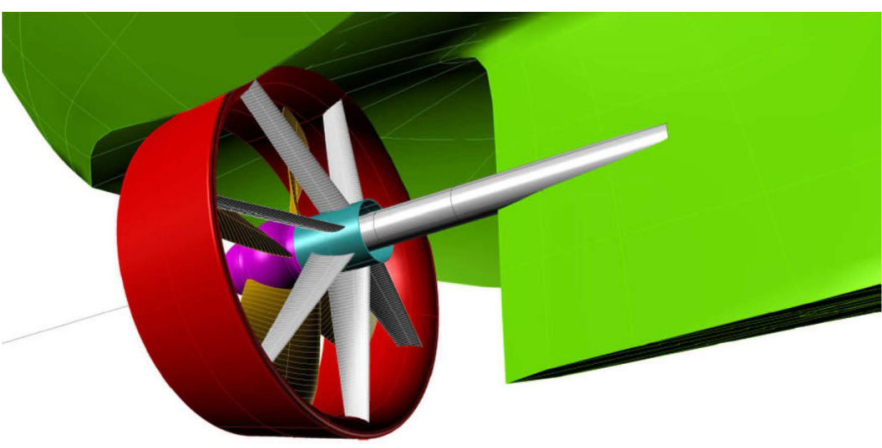

Fig. 7 Retrofit option No.3: Pump propeller

\section{Execution of the demonstrations}

Two types of demonstrations were carried out. The effect on fuel consumption is shown as change of the mean speed running a $1.5 \mathrm{~km}$ straight route in calm water. This simulation was carried out for all cases, with the same engine power.

Although the "Zig-zag" test is commonly used for demonstration of inland vessel manoeuvrability, in this report the turning circle test simulations were performed to demonstrate the effects on manoeuvring capabilities of vessel for all cases. The cause is that the simulator does not contain autopilot algorithm, and the rudder angle change accuracy and dynamics would depend on the operator (helmsman) during the zig-zag tests. The turning circle test can be performed with constant control parameters, what makes this test more objective.

The change in manoeuvrability can be judged by the change in several parameters of the trajectory of the manoeuvres (Fig. 8) and by the swept surface (Fig. 9).

All results of the cases are shown and explained in a short presentation in which the input parameters, the main values, the trajectories are shown, differences are highlighted and explained by a narrative text under the picture. Where necessary and possible, animations are applied. A sample slide can be seen on figure below. Videos of simulations are also available separately (http:// www.moveit-fp7.eu/see-demonstrators-on-simulator.html).

Table 2 Description of the scenarios used in the simulations

\begin{tabular}{|c|c|c|c|}
\hline & Vessel (Length, payload) & Propulsion & Rudder configuration \\
\hline $\begin{array}{l}\text { Case } 1 \\
\text { (as-is situation) }\end{array}$ & $\begin{array}{l}\text { original length } \\
(\mathrm{L}=84.95 \mathrm{~m})\end{array}$ & original & original, 4-bladed conv. rudders \\
\hline Case 2 & $\begin{array}{l}\text { lengthened vessel } \\
(\mathrm{L}=101.45 \mathrm{~m} \text {, original draught, } \\
\text { increased payload) }\end{array}$ & original & original, 4-bladed conv. rudders \\
\hline Case 3 & $\begin{array}{l}\text { original length } \\
(\mathrm{L}=84.95 \mathrm{~m})\end{array}$ & original & $\begin{array}{l}\text { two-bladed } \\
\text { fishtail rudders }\end{array}$ \\
\hline Case 4 & $\begin{array}{l}\text { original length } \\
(\mathrm{L}=84.95 \mathrm{~m})\end{array}$ & original & 3-bladed rudder, Jenckel type \\
\hline Case 5 & $\begin{array}{l}\text { original length } \\
(\mathrm{L}=84.95 \mathrm{~m})\end{array}$ & Pump propeller & original, 4-bladed conv. rudders \\
\hline
\end{tabular}




\subsection{Demonstration of the change of speed}

The change of speed can be demonstrated by performing the simulations for all cases on same course. Starting point and circumstances are the same, the vessel has initially zero speed, than it is accelerated with full throttle. Running the $1.5 \mathrm{~km}$ course the simulation is stopped and the duration and maximum speed reached were stored.

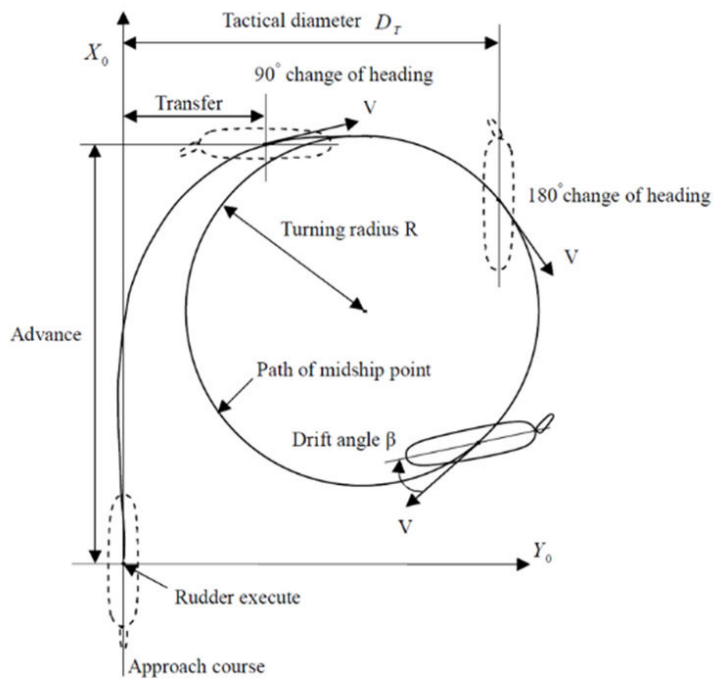

Fig. 8 Parameters of a turning circle test

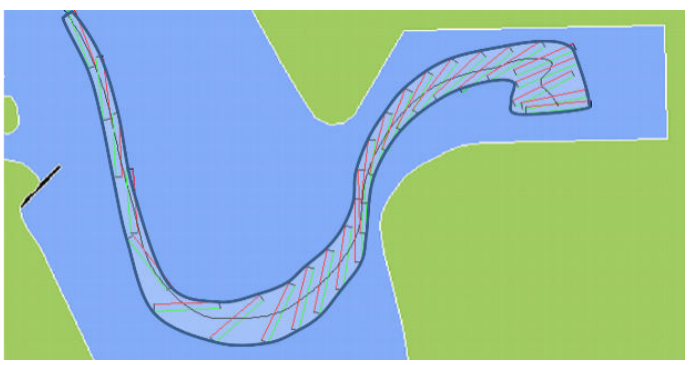

Fig. 9 Swept surface

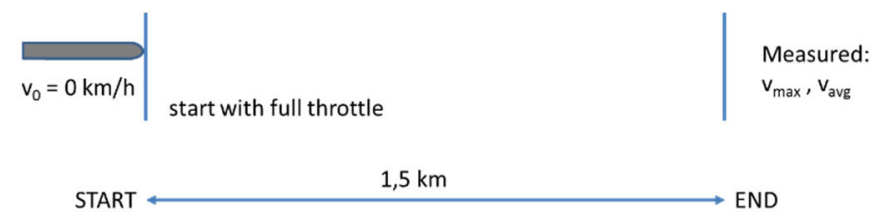

Fig. 10 Illustration of speed change measurement test

Assessment can be made by comparing the average speed as well. The results of simulations are summarised in Table 3 . (Average speed was calculated dividing the length of the run by the duration.)
Table 3 Results of straight running simulations

\begin{tabular}{llll}
\hline & $\begin{array}{l}\text { Duration of run } \\
{[\mathbf{s e c}]}\end{array}$ & $\begin{array}{l}\text { Max. speed reached } \\
{[\mathbf{k m} / \mathbf{h}]}\end{array}$ & $\begin{array}{l}\text { Average speed } \\
{[\mathbf{k m} / \mathbf{h}]}\end{array}$ \\
\hline Case 1 (as-is) & 280 & 22.15 & 19.29 \\
Case 2 & 330 & 21.09 & 16.39 \\
Case 3 & 280 & 21.98 & 19.29 \\
Case 4 & 280 & 22.21 & 19.32 \\
Case 5 & 299 & 21.45 & 18.06 \\
\hline
\end{tabular}

The table shows that the examined cases have nearly the same maximum speed, but the time needed for sailing the same distance is rather different, which can be seen in difference in average speed.

Obviously, the lengthened vessel has the smallest acceleration and average speed due to its greater displacement and resistance. This means greater fuel consumption for the same speed.

Different rudder configuration show small deviations which might be either the result of the proper determination of the decreased total rudder surface and the greater fishtail profile drag.

Examining the Pump Propeller one can conclude that this propulsor type was optimised to the $15-18 \mathrm{~km} / \mathrm{h}$ speed range - as it is known from MoVeIT! research (MoVeIT! project, 2013b). At speeds other than these the stator of the propulsor has greater losses resulting in smaller thrust which leads to the increased duration of the run and the smaller average speed.

\subsection{Demonstration of the change in manoeuvrability}

Turning circle test simulations are performed for all cases in the same way where the ship starts the manoeuver with a predefined speed, which is equal in all cases. Among other parameters, the speed, rate of turn and trajectory of the motion are stored.

The difference in advance, tactical diameter, turning radius, speed decrease and swept area can be displayed and compared by overlaying the trajectories of cases. Speed decrease is calculated by comparing the starting speed with the speed to which the vessel slows down.

Values of important parameters are summarised in Table 4.

Table 4 Results of turning circle test simulations

\begin{tabular}{lllll}
\hline & $\begin{array}{l}\text { Advance } \\
{[\mathbf{m}]}\end{array}$ & $\begin{array}{l}\text { Tactical } \\
\text { diameter }[\mathbf{m}]\end{array}$ & $\begin{array}{l}\text { Turning } \\
\text { radius }[\mathbf{m}]\end{array}$ & $\begin{array}{l}\text { Speed } \\
\text { decrease [\%] }\end{array}$ \\
\hline Case 1 (as-is) & 250 & 210 & 82 & 52 \\
Case 2 & 340 & 351 & 165 & 30 \\
Case 3 & 260 & 240 & 97 & 46 \\
Case 4 & 270 & 223 & 87 & 50 \\
Case 5 & 270 & 223 & 76 & 57 \\
\hline
\end{tabular}


According to the simulations of the previously defined cases the lengthening has the greatest effect on the manoeuvring properties of the vessel. The increased length results in increased weight and added mass as well which in turn reduces the manoeuvrability and improve course keeping. This result a bit contradicts with some previous MoVeIT! study, what concluded the lengthening do not drastically influence on turning. The difference might be because of the accuracy of input parameters (added masses, rudder force coefficients, etc.) of simulation. More accurate results can be achieved by model or full scale tests. However, qualitatively, this trend was also confirmed by the full-mission-bridge simulations carried out in MoVe IT! for the HERSO 1 sailing on the Rhine (MoVeIT! project, 2014).

The selected rudder variations have nearly the same characteristics, the results are strongly depend on the input parameters. The configuration with fishtail profile has greater profile drag and due to its special arrangement and operation the Jenckel-type rudder has also great drag while deflected. Both result in significant speed decrease during turning.

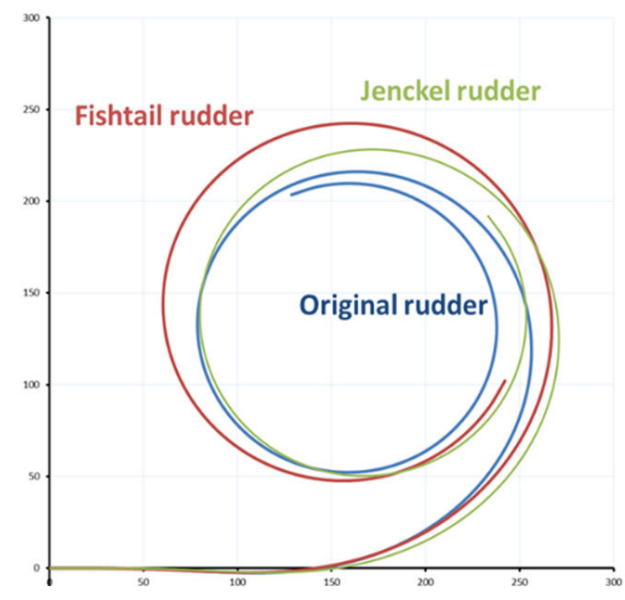

Fig. 11 Illustration of turning circle test simulations for different rudder configuration

The examination of the effect of a Pump propeller is interesting. As it was mentioned earlier, this solution was designed for equal thrust and torque compared to the original solution in the speed range of $15-18 \mathrm{~km} / \mathrm{h}$. This is clearly shown by comparing the turning circles (Fig. 12) of the options: to a certain point (while the vessel speed is in or close to the above speed range) the two trajectories are almost identical. As turning continues, the vessel starts to turn with a smaller radius which shows better rudder efficiency at that slow speeds compared to the original vessel's conventional propeller. The reason can be that the Pump propeller has a thrust at lower speeds greater than the original vessel. However, one should use these results with caution as there are great uncertainties in input parameters of the Pump Propeller (KT and KQ data for 4 quadrants were not available, they were extrapolated and estimated.)

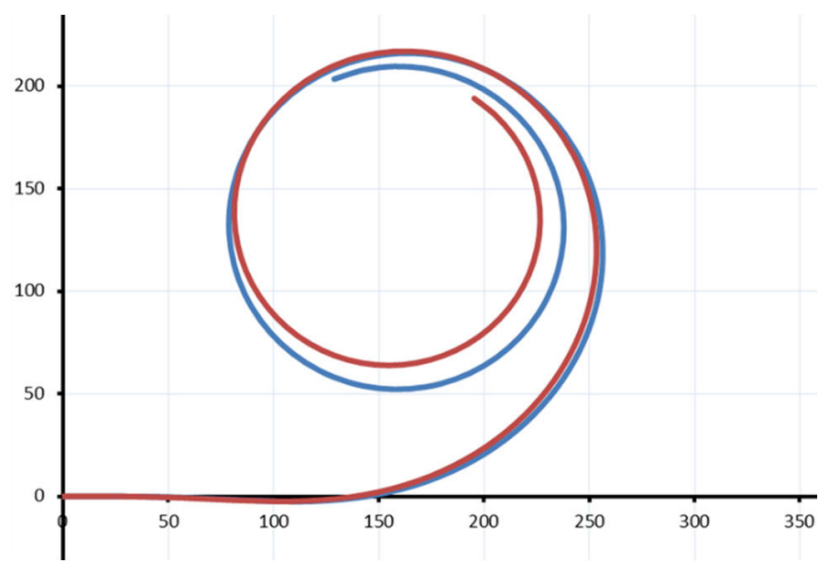

Fig. 12 Illustration of the effect of Pump Propeller on turning circle

Comparison of the cases with regards to swept surface during turning shows very similar results: on one hand swept surface is obviously proportional to the turning circle radius, on the other hand in all cases the width of the swept surface is nearly the same and is approximately 5 times greater than vessel's beam (B). This is true for the lengthened vessel, since it has smaller derivation angles and hence width can be the same (Fig. 13)
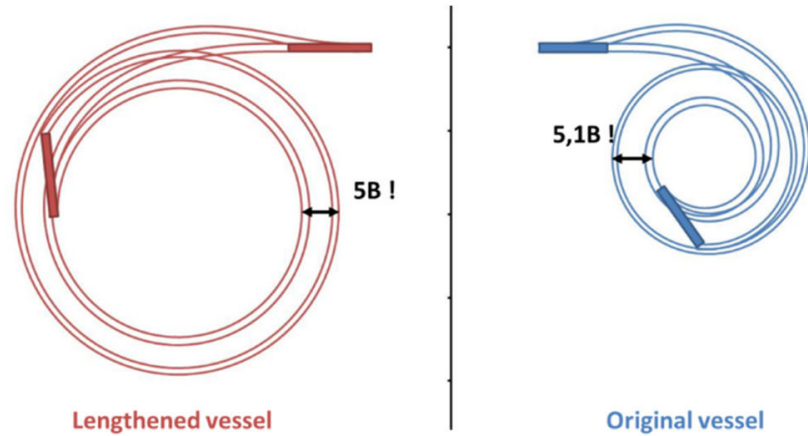

Fig. 13 Swept surface comparison

\section{Conclusions}

Simulator demonstrations were performed with the 2D ship manoeuvring simulator of BME for 5 cases of a motor cargo vessel MV HERSO I. The first case was the as-is situation of the vessel to which different rudder configuration and the effect of Pump Propeller were compared. Achievable speed and manoeuvrability characteristics were examined.

Ship lengthening combined with constant draught showed slower movement of the vessel which would mean greater fuel consumption at same speed but if increased payload is also taken into consideration this retrofit option can be beneficial concerning he specific fuel consumption. Beside this conclusion the increased length results in increased weight and added mass as well which in turn reduces the manoeuvrability and improve course keeping.

The various rudder configuration showed that the 2 bladed fishtail and the Jenckel-type rudders had under $1 \%$ effect on 
ship speed. This is under the measurement error and can be caused by the uncertainty of simulation input parameters. The manoeuvrability also did not changed significantly, only the two bladed fishtail rudder configuration showed larger turning radius. Conclusion of simulations for various rudders is that different arrangements can produce very similar results. For finding a real favourable solution more measurements and/or tests and/or simulations must be made, and an accurate rudder design is needed.

With regards to Pump Propeller one can draw promising conclusions for manoeuvrability. In association with speed potential the simulator tests showed less maximum speed by using Pump Propeller, but by the design speed $(18 \mathrm{~km} / \mathrm{h})$ the original propeller consumed more power, what means higher fuel consumption. For the best operation of the stator-rotor configuration in various combinations of rotational direction of the rotor and water flow direction must be comprehensively examined in the future.

\section{References}

Bertram, V. (2012). Practical Ship Hydrodynamics. $2^{\text {nd }}$ edition, Elsevier Ltd., Oxford, England. 2012.

Brix, J. (1992). Manoeuvring Technical Manual. SeehafenVerlag, Hamburg, Germany.

Hargitai, Cs., Simongáti, Gy., Hadházi, D. (2007). 2D Simulation of inland vessel manoeuvrings. In: $5^{\text {th }}$ European Inland Waterway Navigation Conference, Visegrád, Hungary, Jun. 27-29, 2007, pp. 1-11.

Jankovics, I., Rohács, D., Rohács, J. (2010). Motion simulation model of special acrobatic aircraft. In: Proceedings of 12th Mini Conference on Vehicle System Dynamics, Identification and Anomalies. (Zobory, I. (ed.)), Budapest, Hungary, Nov. 8-10, 2010, pp. 393-401.

MoVeIT! project (2013a). ProjectDeliverable D 7.1 System Integration, (Hekkenberg, R.G. (ed.)), Technical report, Delft University of Technology, Delft, The Netherlands. URL: http://www.moveit-fp7.eu/index.htm1\#downloads
MoVeIT! project (2013b) Project Report T2.2-D2.2 Hydrodynamic improvements, Propeller upgrade, (Tourtelier, A.), Technical report, Ship Studio, Lorient, France. URL: http://www.moveit-fp7.eu/index.html\#downloads MoVeIT! project (2014). Project Deliverable D8.1 - Simulator demonstration of the Herso 1, (Simongáti, Gy.), Technical report, BME, Budapest, Hungary. URL: http://www.moveit-fp7.eu/index.html\#downloads

Nagy, A., Jankovics, I. (2012). Measurement of Small Aircraft Pilot's Reaction Time Variation with Psychological Load in Flight Simulator. Proceedings of AIRTEC, Frankfurt am Main, Germany, Nov. 7-9. 2012. p. 1. Paper 1.

Rohács, D., Voskuijl, M., Siepenkotter, N. (2014). Evaluation of Landing Characteristics Achieved by Simulations and Flight Tests on a Small-Scaled Model Related to Magnetically Levitated Advanced Take -Off and Landing Operations. Proceedings of the 29th Congress of the International Council of the Aeronautical Sciences (ICAS), St. Petersburg, Russia, Sep. 7-12. 2014. Code 108502.

VEB (1973). Binnenfrachtschiff Typ „Europa“ Widerstands- und Propulsionversuchesowie Querkraftmessungen, An-schwenk- und Drehkreisversuche. Versuchsbericht Nr.877. Institut für Schiffbau und Schiffbau-Versuchsabteilung Berlin/Potzdam, 1973. 